\title{
Territorialização da agricultura empresarial em Uruçuí/PI: de "espaço vazio" aos imperativos do agronegócio
}

\author{
Territorialization of business agriculture in Uruçui/PI: from "empty space" to the \\ imperatives of agribusiness
}

Antônio Joaquim da Silva

Doutor em Desenvolvimento e Meio Ambiente e professor do Instituto Federal de Educação, Ciência e Tecnologia do Piaú, Brasil antoniojoaquim@ifpi.edu.br

Maria do Socorro Lira Monteiro

Doutora em Economia Aplicada e professora do Departamento de Ciências Econômicas da Universidade Federal do Piauí, Brasi

socorrolira@uol.com.br

Eriosvaldo Lima Barbosa

Instituição/Afiliação

Doutor em Cultura e Sociedade e professor do Departamento de Planejamento e Política Agrícola da Universidade Federal do Piauí, Brasil eriosvaldobarbosa@hotmail.com

\begin{abstract}
Resumo
O processo de expansão da fronteira agrícola no cerrado piauiense, comandada pelo agronegócio, consubstancia-se como o fenômeno responsável por transformações socioespaciais que atingem diretamente a organização do território. Este estudo qualiquantitativo tem como objetivo analisar os fatores responsáveis para a consolidação da agricultura empresarial no município de Uruçuí/PI e as consequências desse fato para a posse e uso da terra e para a agricultura familiar. Uruçuí se destaca pelo pioneirismo em abrigar empreendimentos graníferos no Estado e a disponibilizar infraestrutura para o agronegócio e liderar o ranking de municípios com o melhor PIB per capita. A investigação sustentou-se no método dialético, cujos procedimentos técnicos basearam-se nas pesquisas bibliográfica, documental e levantamento, como também na aplicação de entrevistas semiestruturadas entre três empreendimentos graníferos, selecionados por acessibilidade e em razão do tempo de instalação em Uruçuí, em distintos períodos. Concluiu-se que a chegada da agricultura empresarial no município inicia nos anos 1980 e intensifica-se na década de 1990, cujos motivos para a instalação se referiram, a priori, ao baixo preço das terras, às condições geoambientais e à existência de um mercado regional. E a posteriori, vincularam-se à infraestrutura implantada para financiar, produzir, armazenar e distribuir as mercadorias, bem como a ampliação da participação do país no mercado internacional, tendo o Estado papel relevante nesse processo, o que repercutiu na continuidade da pequena produção familiar.
\end{abstract}

Palavras-chave: agricultura empresarial, agronegócio, cerrados, soja, território.

\begin{abstract}
The process of expansion of the agricultural frontier in the Piauí Cerrado, controlled by agribusiness, has become the phenomenon responsible for socio-spatial transformations that directly affect the organization of the territory. This qualitative and quantitative study aims to analyze the factors responsible for the consolidation of business agriculture in the city of Uruçuí/PI and the consequences of this fact for land tenure and land use and for family farming. Uruçuí stands out for being the pioneer in housing large grain enterprises in the state and in providing infrastructure for
\end{abstract}


agribusiness and to lead the ranking of municipalities with the best GDP per capita. The research was based on the dialectical method, whose technical procedures were based on bibliographical and documentary research, data survey, as well as the application of semi-structured interviews with three grain enterprises, selected for their accessibility and also for the time of installation in Uruçuí, in different periods. It was concluded that the arrival of business agriculture in the city began in the 1980 and it was intensified in the 1990, whose reasons for its installation are due to the low land prices, to the geo-environmental conditions and the existence of a regional market. Subsequently, they were linked to the infrastructure implemented to finance, to produce, to store and distribute the goods, as well as the expansion of the country's participation in the international market, considering that the State played an important role in this process, which had repercussions on the continuity of small family production.

Keywords: business agriculture, agribusiness, cerrados, soybean, territory.

\section{INTRODUÇÃO}

O processo de expansão do agronegócio para as áreas de fronteira agrícola, como o bioma Cerrado, tem potencializado a reprodução do capital, e ao mesmo tempo, tem causado mudanças que atingem diretamente o trabalho, a paisagem, as sociabilidades e a terra.

Tal configuração sublinha que a agricultura empresarial, atividade comandada pelo agronegócio, cujo perfil se assenta na produção agrícola, visando à proeminência do capital, se intensificou de maneira itinerante, dependente do incremento de inovações tecnológicas, de terra e do mercado externo (SILVA, 2016).

Para Ribeiro, Mendonça e Hespanhol (2002), a agricultura empresarial evoluiu ocupando novas áreas agricultáveis, alterando as relações sociais de produção, reduzindo a mão de obra e aumentando a produtividade da terra e do trabalho.

Esse cenário decorre, sobretudo, da contextualização do agronegócio, que de acordo com Silva, Monteiro e Silva (2015), constitui um projeto sociopolítico personificado em torno de um pequeno grupo de capitalistas agrários que defendem a participação do Estado na concessão de benesses de um segmento social que produz para o mercado de commodities, por sua vez, articulado aos imperativos do mercado financeiro mundial.

Corroborando, Silva, Monteiro e Barbosa (2016) consideram o agronegócio uma forma moderna de apropriação do espaço rural, que se organiza estrategicamente sob novas bases produtivas e de gerenciamento.

Não obstante tal conformação, registra-se que a partir dos anos 1990, os cerrados piauienses tornaram-se palco da instalação e expansão de grandes empreendimentos graníferos, para produzirem, sobretudo soja (Glycine max (L.) Merr.), tendo as políticas públicas dos governos federal e estadual participação essencial nesse contexto (SILVA, 2016). 
Por conta disso, no sudoeste piauiense, o avanço sistemático do agronegócio tem intensificado as inovações tecnológicas, conferindo à fronteira elevada produtividade agrícola, a tendência de aumento dos lucros, o acirramento dos conflitos sociais e a degradação dos recursos ambientais (SILVA; MONTEIRO; BARBOSA, 2017).

Na referida região, destaca-se Uruçuí, por ter sido um dos primeiros municípios a receber empreendimentos graníferos e disponibilizar infraestrutura para o agronegócio, o que tem repercutido na conversão do cerrado local como mercadoria para o agronegócio, revelada na substituição da cultura extensiva por intensiva (MORAES, 2009; SILVA, 2016).

Até o final dos anos 1990, o cerrado piauiense era concebido pelo Estado como um espaço vazio (MORAES, 2006, 2009; BERNARDES, 2009). Logo, em razão do baixo dinamismo econômico e populacional, coube às políticas estatais a função de viabilizar a entrada da agricultura empresarial no território (SILVA, 2016). Inclusive para Lopes (2008), antes da chegada do agronegócio, o cerrado piauiense apresentava poucos núcleos urbanos, baixa densidade demográfica rural, isolamento das comunidades, sobretudo nos fundos de vales, e presença de grandes propriedades criadoras de gado.

Sendo assim, faz-se necessário questionar o processo de territorialização da agricultura empresarial em Uruçuí, por espelhar dinâmicas e dilemas da reprodução do capital. Este artigo pretende analisar os fatores responsáveis para a consolidação da agricultura empresarial no município e as repercussões socioespaciais da ocupação, mormente para a posse e o uso da terra e para o cotidiano das populações locais.

\section{NOTAS SOBRE TERRITORIALIDADES: LÓGICAS E ESTRATÉGIAS ESPACIAIS}

De acordo com Sack (1986), a territorialidade é uma estrutura de poder, uma estratégia espacial que sustenta um conjunto de ações, comportamentos e meios para controlar fenômenos, indivíduos e recursos. Dessa maneira, assinala que a territorialidade combina saberes e práticas sociais marcadas pela posse e acessibilidade sobre uma determinada fronteira.

Corroborando, Comerci (2010) sublinha que a territorialidade é uma atividade relacional e comunicativa que põe em destaque habilidades para estar com os "Outros" (outsiders), compartilhar situações e viver experiências. Assim sendo, frisa que as territorialidades qualificam as relações de poder, por realçarem o controle material/simbólico do território.

Já Raffestin (1987) constata que a territorialidade é uma especificidade humana, já que não é apenas feita de relações com os territórios concretos, mas por relações com os territórios abstratos como línguas, religiões, tecnologias, etc, constitui uma linguagem que os homens fazem do mundo, materializada por meio da articulação de malhas, nós e redes (originados por instrumentos técnicos 
de desenvolvimento econômico, social, político e cultural), cuja finalidade se centra na apropriação e consumo de recursos, visando alcançar a autonomia. Diante disso, respalda que a territorialidade denota um conjunto de células (malhas), definidas a partir de um nó que está ligado por uma rede, que é estável e, portanto, projeta o território.

As considerações de Sack, Raffestin e Comerci se aproximam das opiniões de Menestrino e Parente (2011), de que a territorialidade corresponde ao desdobramento das relações humanas legitimadas através dos vínculos entre sociedade e geoambiente, demonstrados por meio da produção de bens, de moradias, de interações de trocas internas e externas, etc.

Para Andrade (1994, p.214), a territorialidade esboça afetividades que surgem nas pessoas por participarem da ordenação do território. Desse modo, admite que a territorialidade deve ser captada como uma categoria temporária, uma vez que no espaço e no tempo nada é permanente, tudo se encontra em constante transformação. Isto significa que:

A expressão territorialidade pode ser encarada tanto como o que se encontra no território e está sujeita à gestão do mesmo, como, ao mesmo tempo, ao processo subjetivo de conscientização da população de fazer parte de um território, de integrar ao território.

Tal opinião de Andrade também é reforçada por Saquet (2004, p.133), quando comenta que territorialidade é multiforme, cotidiana. Ou seja, a territorialidade valida a complexidade social a qual o processo de construção de cada território é inerente, de cada lugar, bem como as relações de exploração dos patrimônios físico e cultural pelo capital. Por conseguinte, visando aprofundar a percepção sobre a realidade dos territórios, opta pela terminologia territorialização, por possibilitar o incremento e a difusão "de novas forças mercantis ao processo de re-produção ampliada do capital; permite o acesso a específicas condições de trabalho e de consumo, de conhecimentos, de infraestruturas, etc".

Em sentido análogo, Corrêa (2006, p.35) personaliza a lógica da territorialização a partir das práticas espaciais, concebidas como "ações que contribuem para garantir os diversos projetos. São meios efetivos através dos quais se objetiva a gestão do território, isto é, a administração e o controle da organização espacial em sua existência e reprodução". Desse modo, identifica duas práticas espaciais exclusivas da territorialização, a seletividade e fragmentação. A primeira se traduz por meio da escolha de um determinado lugar, conforme os atributos considerados vantajosos para os diversos interesses estabelecidos; e a segunda, deriva da intensidade de atuação de uma empresa ou grupo, através da implantação de um maior número de unidades sobre certa área, onde as características físicas e socioeconômicas propiciassem a potencialização do capital.

Nessa perspectiva, faz-se mister acentuar, de acordo com Saquet (2004, p.128) que: 
Sucintamente, o processo de territorialização é um movimento historicamente determinado pela expansão do capitalismo e seus aspectos culturais; é um dos produtos socioespaciais do movimento e das contradições sociais, sob a tríade economia, política e cultura (EPC), que determina as diferentes territorialidades, no tempo e no espaço, as próprias desterritorialidades e as re-territorialidades. A perda e a constituição de um novo território nascem no seio da própria territorialização e do próprio território. Contraditoriamente, a des-territorialização é composta por processos socioespaciais concomitantes e complementares.

Mas para Haesbaert (2004, 2013), a territorialização é, sobretudo, enraizadora, pois proporciona a coesão espacial, por ter detalhe mais intrínseco e introvertido, e por estar ligada à trama político/cultural de apropriação e domínio dos territórios.

Já Baby-Collin et al. (2011) definem a territorialidade a partir das atividades cotidianas, devido espelharem os contextos de convívio social relevantes na elaboração do espaço geográfico. Acrescentam ainda, que a territorialidade provoca sentidos aos lugares (de trabalho, de residência, de consumo e de sociabilidades), e ao mesmo tempo, articula-os, a fim de construir os territórios.

Por outro lado, Floriani, Ríos e Floriani (2013, não paginado) entendem a territorialidade como uma alternativa de reação contra os imperativos da hegemonia de classes dominantes no mundo rural (do agronegócio, por exemplo). Em vista disso, salientam que as territorialidades representam o resultado de um duplo processo de aprendizagem e/ou adaptação, sendo um interno ao próprio território (proveniente da coevolução entre ecossistemas e pessoas), e outro externo e entre territórios (que envolve disputas geopolíticas). Logo, verificam que:

[...] as particularidades socioambientais dos territórios tradicionais, particularmente das regiões onde as práticas produtivas modernas se fazem difíceis - tal como as regiões montanhosas, desérticas ou alagadas, nas pequenas faixas de praia, mangues e baías conseguem impor limites às formas de racionalização do espaço, fazendo com que as práticas produtivas sejam ressignificadas, revalorizadas pelas comunidades de acordo com as histórias co-evolutivas impressas em seus territórios, o que se traduz em termos de híbridos de práticas e concepções moderno-tradicionais. [...] Os discursos sobre os atributos reprodutivos da natureza, interpretados como visões e projetos de mundo - as territorialidades - materializam-se em tipos de paisagens puras e híbridas: desde os centros de poder do capital globalizam-se as paisagens da homogeneização, aquelas que simbolizam uma racionalidade econômico-instrumental stricto sensu (ex. as paisagens das monoculturas agrícolas, ou dos traços retos e uniformes e da velocidade nas cidades planejadas), onde prevalecem a uniformidade e a simplificação do pensamento e da natureza, cuja finalidade é a otimização da produção dos fluxos de energia, matéria e informação.

As colocações de Floriani, Ríos e Floriani vão ao encontro da afirmação de Haesbaert (2004, p.114) de que o debate sobre o controle, ordenamento e gestão do território, no qual se incluem também as questões ambientais, têm sido cada vez mais centrais nas rediscussões sobre o papel das políticas territoriais, já que: 


\begin{abstract}
A implementação das chamadas políticas de ordenamento territorial deixa mais clara a necessidade de considerar duas características básicas do território: em primeiro lugar, seu caráter político - no jogo entre os macropoderes políticos institucionalizados e os "micropoderes", muitas vezes mais simbólicos, produzidos e vividos no cotidiano das populações; em segundo lugar, seu caráter integrador - o Estado em seu papel gestordistributivo e os indivíduos e grupos sociais em sua vivência concreta como os "ambientes" capazes de reconhecer e de tratar o espaço social em todas as suas múltiplas dimensões.
\end{abstract}

Assim, entende-se que territorialização e territorialidade são expressões ambivalentes e recíprocas, que dizem respeito às dinâmicas políticas, econômicas e culturais que dão identidade aos territórios. Tais categorias conferem distintos processos, principalmente, concreto/funcionais e utilitário/significativos, nos quais predominam relações marcadas por poder e carga simbólica, ditas preponderantes para o controle (dominação) e apropriação (simbolismo) dos territórios.

\title{
3. CERRADO PIAUIENSE: DE "ESPAÇO VAZIO" À OCUPAÇÃO CAPITALISTA
}

De acordo com a CEPRO (2014), os cerrados piauienses ocupam 46,0\% do território estadual, com 11,5 milhões de hectares, o que corresponde a 6,0\% da totalidade dos cerrados no país. Adenda ainda que relativo à distribuição espacial dos cerrados piauienses, o sudoeste compreende a região onde predomina extensas áreas do bioma no Estado.

Brandão Filho (2009) constata que as terras que atualmente estão sendo incorporadas ao domínio do agronegócio granífero no Piauí, as quais incluem Uruçuí, foram colonizadas no século XVII, nos marcos das demandas da pecuária extensiva e da coleta de produtos nativos, cabendo aos latifundiários baianos e pernambucanos a titulação das primeiras sesmarias. Explicita que entre a segunda metade do século XIX e meados do século XX, inicia-se o cultivo do algodão (Gossipium hirsutum L.) e, secundariamente, da cana-de-açúcar (Saccharum officinarum L.), que permitiram o ingresso do Estado ao mercado internacional, além do comércio de mercadorias do extrativismo vegetal, como a carnaúba (Copernicia prunifera (Mill.) H. E. Moore), a maniçoba (Manihot glaziovii Müll. Arg.) e o babaçu (Attalea speciosa Mart. ex Spreng), cuja exportação diminuiu a partir dos anos de 1950. Tal cenário provocou a expansão das lavouras de arroz (Oriza sativa L.), milho (Zea mays L.), feijão (Phaseolus vulgaris L.) e mandioca (Manihot esculenta Crantz) no mercado doméstico, devido à crescente urbanização do país e melhorias na infraestrutura rodoviária e fluvial de rios navegáveis, principalmente o rio Parnaíba.

Outrossim, de acordo com Moraes (2006), as terras situadas no sul do Estado faziam parte de um circuito comercial centrado no rebanho de corte, concentrador de terras e revelador de personagens figurativos da tradição rural regional, como vaqueiros, índios, escravos, posseiros ${ }^{1}$,

\footnotetext{
${ }^{1}$ Posseiros referem-se aos trabalhadores que mantêm vínculo com a terra através de relações de posse, pois não detém o título jurídico da propriedade (MORAES, 2009).
} 
agregados $^{2}$ e cultivadores livres ${ }^{3}$. No entanto, sublinha que em razão do baixo dinamismo econômico e do isolamento geográfico populacional, o sudoeste piauiense foi historicamente concebido como um espaço detentor de um vazio socioeconômico e cultural que perdurou até meados do século XX, quando as ações dos governos federal e estadual materializaram uma nova ocupação da fronteira produtiva, alicerçada em empresários e investidores do capital agrário.

Conforme Alves (2003), as áreas de chapadas ou terrenos planos e/ou suavemente ondulados dos cerrados piauienses, tradicionalmente chamadas de Gerais, representavam para as famílias nativas, como as camponesas, os lugares de uso comum, ou seja, designavam as áreas de reservas naturais onde se soltava o gado para o proveito da pastagem (em determinadas épocas do ano), ou serviam de lugar de extrativismo vegetal (lenha, frutos, raízes, cascas e plantas medicinais) e de caça de animais silvestres. Os Gerais simbolizavam as terras devolutas, isto é, terras ociosas e não cercadas, que constituíam extensos descampados de matas de cerrados. Para tanto, esclarece que:

No contexto social local, as terras dos Gerais significavam um lugar de vital importância
para a manutenção do modo de vida das comunidades camponesas. Seu equilíbrio se
mantinha pelo uso privado das roças, na vazante, e pelo que se podia aproveitar, sem
qualquer impedimento, dos recursos existentes nos Gerais. [...] A modernização
contemporânea, a partir da instalação de novos agentes econômicos dos cerrados
piauienses, significou uma importante metamorfose no uso das terras dos Gerais: de espaço
de uso tradicional explorado comunitariamente pelas necessidades concretas de vida da
população local passa para espaço privado destinado à agricultura capitalista moderna. As
terras dos Gerais tornam-se mercadorias, pois são colocadas no mercado imobiliário
apresentando uma rápida valorização. Poucas delas são efetivamente cercadas, mas a
configuração da propriedade particular aparece nitidamente delimitada: às vezes, são as
lavouras de soja, milho, algodão ou solos desnudos em imensos descampados que
explicitam os limites da propriedade (ALVES, 2009, p.168).

Ademais, Peixinho e Scopel (2009, p.111) preconizam que a retirada da vegetação dos Gerais "não só produziu um grande impacto ambiental, mas, sobretudo, comprometeu o modo de vida dessa população". Nesse sentido, faz-se possível enfatizar a opinião de Bernardes (2015, p.507) de que "fenômenos de abertura de novos espaços produtivos e de cooperação podem ser identificados, vinculados a novos potenciais, com suas múltiplas influências e condicionantes, bem como a fenômenos de fechamento de espaços tradicionais".

Portanto, ressalta-se que o reconhecimento da potencialização do agronegócio no cerrado piauiense se circunscreve no processo de globalização da economia brasileira, caracterizado pelo incremento técnico/científico/informacional na agropecuária, o que exigiu a reestruturação

\footnotetext{
${ }^{2}$ Agregados são agricultores que moram no local de trabalho e pagam aluguel para explorar a terra (FERREIRA, 2009).

${ }^{3}$ Cultivadores livres eram escravos libertos dos quilombos, colonos ou mestiços, que se instalaram nas terras isoladas ou disponíveis nos interstícios das grandes propriedades rurais situadas principalmente nas regiões Agreste e Sertão do Nordeste brasileiro, para produzirem culturas alimentares e criarem animais destinados a abastecer os mercados locais e as fazendas monocultoras (SABOURIN, 2009).
} 
produtiva do espaço rural, marcada pela territorialização do capital e pela oligopolização do uso da terra, redundando em formas mais avançadas de produção, de circulação e de consumo.

\section{METODOLOGIA}

\subsection{Caracterização da área de estudo}

Historicamente, a formação de Uruçuí data de 23 de junho de 1902, por meio da Lei Estadual $n^{\circ} 290$, que elevou à categoria de distrito o povoado Nova Vila, o qual pertencia ao município de Bertolínia. A instalação da sede municipal ocorreu em 27 de setembro daquele ano, e que o motivo para a denominação relacionou-se aos fatores ambientais, haja vista que as terras ocupadas localizam-se no vale do rio Uruçuí Preto, que deságua no rio Parnaíba (IBGE, 2017).

Uruçuí possui área territorial de $8.452,025 \mathrm{~km}^{2}$, com sede situando-se nas coordenadas geográficas $07^{\circ} 13^{\prime} 46^{\prime \prime}$, latitude Sul e, 44³3'22”, longitude Oeste, e apresenta como limites geopolíticos, ao Norte, o estado do Maranhão e o município piauiense de Antônio Almeida, ao Sul, Alvorada do Gurgueia e Palmeira do Piauí, ao Leste, Sebastião Leal, Landri Sales e Manoel Emídio e, a Oeste, Baixa Grande do Ribeiro, Ribeiro Gonçalves e o estado do Maranhão. Em âmbito regional, o município localiza-se na Mesorregião Geográfica Sudoeste Piauiense, onde predomina extensas áreas do bioma Cerrado no Estado (SILVA, 2016).

Conforme o IBGE (2010), neste ano, Uruçuí contava com um Índice de Desenvolvimento Humano Municipal (IDHM) de 0,631, e com uma população de 20.149 habitantes, cuja distribuição espacial distinguia-se em 15.506 e 4.643 habitantes nas zonas urbana e rural, respectivamente.

Segundo a CEPRO (2016), em 2014, Uruçuí contabiliza a quarta colocação no ranking dos municípios piauienses com significativo Produto Interno Bruto (PIB), com R\$ 954.285.000,00 e o maior PIB per capita, com $\mathrm{R} \$ 45.655,18$. Esse excepcional desempenho decorreu do Valor Adicionado (VA) da produção agropecuária, computado em R \$ 274.555.000,38.

Além do mais, Uruçuí patenteia relevante performance sobre o rendimento médio da produção granífera, sobretudo, soja, pois em 2014, registrou a quantia de $2.185 \mathrm{~kg} /$ hectares, o que possibilitou superar a média estadual de $2.146 \mathrm{~kg} / \mathrm{hectares}$ e conferir-lhe a segunda posição entre os municípios produtores (IBGE, 2015).

\subsection{Classificação da pesquisa e procedimentos para a coleta e análise dos dados}

Esta investigação se embasou no método dialético, que segundo Sposito (2004), é ideal à formatação da verdade por refutar as opiniões do senso comum, quando estas são expostas às próprias contradições. Assentou-se também nas análises qualiquantitativas, por circunscrever a 
inter-relação dos dados estatísticos e qualitativos (KIRSCHBAUM, 2013). Logo, trata-se de uma investigação descritiva/explicativa, no qual o pesquisador ao não controlar eventos e variáveis, busca descrever, interpretar e avaliar a complexidade de uma realidade, processos e fenômenos (SANTOS, 2012).

O estudo elegeu os imóveis rurais que apresentavam dimensões acima de 15 módulos fiscais. Brasil (1993) esclarece que o módulo fiscal estabelece a área mediana dos módulos rurais dos municípios, classificando-os quanto ao tamanho, na forma da Lei ${ }^{\circ} 8.629$, de 25 de fevereiro de 1993, a qual distingue para fins de reforma agrária a pequena propriedade (imóvel rural com área compreendida entre um e quatro módulos fiscais), a média propriedade (imóvel rural com área entre quatro e 15 módulos fiscais) e a grande propriedade (imóvel rural com área maior que 15 módulos fiscais). Em Uruçuí, o módulo fiscal corresponde a 75 hectares (INCRA, 1980, 2013).

Essas grandes propriedades, segundo Aguiar e Monteiro (2005), configuraram-se em reais representantes do agronegócio, haja vista utilizarem inovações tecnológicas, produzirem em larga escala, financiarem a produção e empregarem trabalhadores temporários, mão de obra assalariada e originária da agricultura familiar tradicional. Além disso, considerou-se o tempo de instalação dos empreendimentos em Uruçuí, preferivelmente, em distintos períodos, para constatar diferenças ou não no processo de ocupação das chapadas e na racionalidade produtiva.

Em função dessa conformação, definiu-se para compor o estudo três empreendimentos graníferos, instalados em 1995, 1997 e 2012, os quais foram selecionados intencionalmente, ou seja, pelo pesquisador, em virtude das características descritas anteriormente e por estarem disponíveis (acessíveis) para compor a amostra. A Figura 1 apresenta a localização espacial dos empreendimentos investigados.

As coletas foram realizadas entre os meses de fevereiro a julho de 2015, por meio de formulários e entrevistas semiestruturados, com questões guias sobre os motivos para instalação em Uruçuí, a propriedade e uso da terra e a força de trabalho empregada. Utilizou-se ainda gravador de áudio para registrar/descrever os fatos com que se estava lidando.

Os dados quantitativos foram tratados mediante o uso do programa eletrônico Microsoft Planilha Excel 2012. A análise qualitativa dos discursos gravados, reconheceu-se a necessidade de transcrição e leitura das falas, respeitando os depoimentos dos produtores para possibilitar a “compreensão de como um objeto simbólico produz sentidos, como ele está investido de significados para e por sujeitos" (ORLANDI, 2000, p.61).

Este trabalho socializa parte dos resultados de uma pesquisa de doutorado realizada pela Universidade Federal do Piauí, e registrada no Parecer Consubstanciado de Aprovação Ética, sob o número 1087335, o qual permitiu assegurar o anonimato dos informantes, com vistas a preservar as 
identidades, uma vez que para Verónica e Sotomayor (2011), as opiniões pessoais, a vida privada e a intimidade familiar são suscetíveis de proteção.

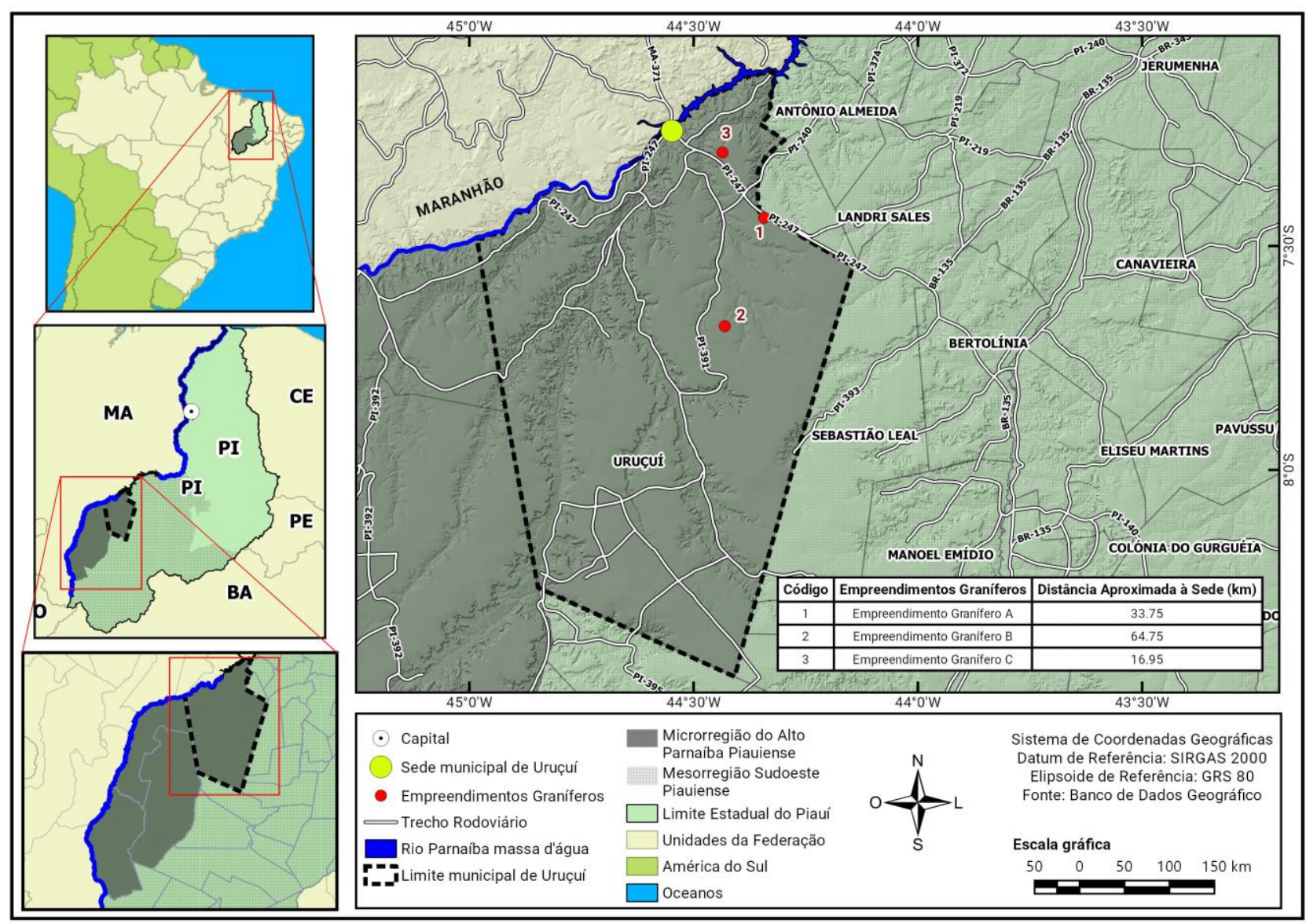

Figura 1 - Mapa da localização geográfica dos empreendimentos graníferos em Uruçuí/PI Fonte: Dantas (2017) com base em IBGE (2014).

\section{RESULTADOS E DISCUSSÕES}

No âmbito dos empreendimentos pesquisados, constatou-se que $66,7 \%$ dos graníferos apontaram o preço da terra como aspecto relevante para a definição de Uruçuí como área de atração do agronegócio, enquanto 33,3\% dos empresários agrícolas indicaram a infraestrutura montada, sobretudo, pela ação estatal, como principal requisito para a sustentação da produção. Esse cenário revelou por um lado, que o baixo valor das terras uruçuienses foi determinante à seletividade espacial, especificamente, no final da década de 1980, período no qual desembarcaram os primeiros produtores e investidores econômicos, e por outro lado, a infraestrutura disponibilizada pelos sucessivos governos estaduais apresentou-se como imperativo à continuidade do processo de incorporação do cerrado à cadeia de grãos, na medida em que implicou a construção de rodovias, redes elétricas, indústrias de sementes, plantas 
esmagadoras de grãos, armazéns, comércio de máquinas, indústrias de fertilizantes, serviços especializados, etc., para dar suporte à chegada de novos produtores e empresas de agronegócios.

Com relação a terra, verificou-se, em consonância com os relatos dos fazendeiros mais antigos, que o baixo preço foi conditio sine qua non para a chegada de pessoas procedentes de vários lugares do Brasil, interessadas em produzir nas chapadas de Uruçuí, como explicou um produtor rural:

O motivo para se instalar em Uruçuí foi o preço da terra. Na época [1995], o preço da terra, por hectare, aqui em Uruçuí, era bem mais atrativo [barato] do que o preço da terra arrendada, é [...], paga, é, por hectare, de outros lugares, como a Bahia, o Sul e o Centro-Oeste do país [...] (Comunicação oral).

Por meio desse depoimento, notou-se que a migração para Uruçuí representou a possibilidade de o produtor se libertar da antiga condição de pequeno proprietário ou de rendeiro em propriedade de outrem, nos cerrados do Centro-Oeste ou de outras terras do país. Adenda-se que os graníferos por serem descendentes de europeus, já possuíam vínculos com a agricultura de base familiar. Tal situação se coadunou com a análise de Alves (2006, p.243), de que os migrantes chegaram no cerrado com capital suficiente para adquirirem "grandes extensões de terras, transformando uma parte delas em unidade produtiva de grãos de médio e grande porte, principalmente soja, e deixando a outra parte como reserva de valor". Ao mesmo tempo, o migrante sulista (no Nordeste, as tipologias sulistas, gaúchos ou pioneiros designam os Outros, isto é, aqueles que chegam para ocupar o território), “em sua trajetória por outra fronteira agrícola, foi acumulando riquezas, tornando-se inclusive um grande empresário do setor do agronegócio. Mas, na sua origem, muitos deles eram camponeses com pouca ou nenhuma terra”.

Depreendeu-se, alicerçado na pesquisa de campo, que a propriedade da terra se apresentava como elemento central no processo de territorialização da agricultura em moldes empresariais em Uruçuí, institucionalizada por meio de uma segurança jurídica orquestrada pelo Estado, uma vez que para Peixinho e Scopel $(2009$, p.106) “a segurança da propriedade privada não está no seu uso imemorial pelas populações tradicionais, mas no reconhecimento, pelo Estado, dos que detêm o direito da propriedade".

Em razão dessa contextura, Peixinho e Scopel (2009, p.106) acrescentam que as populações tradicionais, que "historicamente detinham o uso das áreas, mas não têm o documento formal dessas áreas, estão sendo excluídas do acesso à terra". Que "o território de uso é subordinado à territorialização do institucional, alimentando a ideia de que a fronteira se estabelece no limiar entre o "legal" e o uso, mesmo que esteja historicamente estabelecido". E que a maneira como o governo estadual, por meio do Instituto de Terras (INTERPI) e em nome do desenvolvimento econômico, engendrou para legalizar essas áreas, foi "recolhê-las para, em 
seguida, leiloá-las a preços módicos aos que hoje detêm suas posses. Dessa forma, o Estado se coloca como único ente com poder legal para instituir a propriedade privada "legal".

A partir desse cenário, verificou-se que tal tendência concentracionista da estrutura fundiária permanecia, pois segundo dados do Sistema Nacional de Cadastro Rural (SNCR), criado pelo INCRA, até o ano de 2013, as médias e grandes propriedades, que representavam 41,8\% (536 unidades) do total de imóveis rurais de Uruçuí, fixado em 1.282 unidades, ocupavam 52,6\% (112.456,507 ha) do universo de 213.748,402 hectares. E que os imóveis rurais cujas dimensões não ultrapassavam quatro módulos fiscais (minifúndio e pequena propriedade), correspondiam a 57,8\% (741 unidades) da totalidade, isto é, abrangiam 46\% da área ocupada, definida em 98.250,595 ha (INCRA, 2013).

Com efeito, detectou-se que o agronegócio preponderava nas grandes propriedades rurais, já que $100 \%$ dos empreendimentos incorporavam o grupo de área de 3.000 e mais ha, conforme exposto na Tabela 1.

Tabela 1 - Estrutura fundiária dos empreendimentos graníferos de Uruçuí/PI, segundo os empresários agrícolas

\begin{tabular}{c|c|c|c|c|c}
\hline $\begin{array}{c}\text { Empreendimento } \\
\text { granífero }\end{array}$ & $\begin{array}{c}\text { Área cultivada } \\
\text { (ha) }\end{array}$ & $\begin{array}{c}\text { Área destinada } \\
\text { para novos } \\
\text { plantios (ha) }\end{array}$ & $\begin{array}{c}\text { Área de } \\
\text { Reserva } \\
\text { Legal }^{4} \text { (ha) }\end{array}$ & $\begin{array}{c}\text { \% de área } \\
\text { cultivável }\end{array}$ & Área total (ha) \\
\hline A & 9.700 & 3.600 & 5.700 & 51,0 & 19.000 \\
B & 3.000 & 2.026 & 2.200 & 41,5 & 7.226 \\
C & 1.800 & 440 & 960 & 56,2 & 3.200 \\
\hline
\end{tabular}

Fonte: Pesquisa direta, fevereiro/julho de 2015.

Por meio da Tabela 1, observou-se que 49,3\% da área total das fazendas pesquisadas eram produtivas e 50,7\% improdutivas, o que revelou que os métodos de cultura intensiva implementados pelos graníferos canalizavam a manutenção de um excedente de terra, destinado à formação de novos plantios e uma área auxiliar, sobretudo, para Reserva Legal, haja vista que $100 \%$ dos produtores cumpriam a legislação ambiental por reconhecerem a licença ambiental ${ }^{5}$ como instrumento normativo. Dessa maneira, identificou-se com base na pesquisa que, dos 29.426 ha ocupados pela agricultura empresarial, apenas 14.500 ha estavam dedicados à produção.

\footnotetext{
${ }^{4}$ Sublinha-se que os graníferos calculavam o montante de área a ser preservada, por meio do Decreto Estadual $\mathrm{n}$. 11.126, de 11 de setembro de 2003, artigo $5^{\circ}$, que estabelece que $30 \%$ da área da propriedade averbada seja destinada para Reserva Legal.

5 É o ato administrativo no qual o órgão ambiental competente define as condições, restrições e ações de controle ambiental que "deverão ser obedecidas pelo empreendedor, pessoa física ou jurídica, para localizar, instalar, ampliar e operar empreendimentos ou atividades utilizadoras dos recursos ambientais consideradas efetiva ou potencialmente poluidoras ou aquelas que, sob qualquer forma, possam causar degradação ambiental" (CONAMA, 1997, p.644).
} 
Tendo em vista essa conformação, percebeu-se o quão é atual a crítica de Kautsky (1986, p.132), que o tamanho máximo de uma propriedade rural com "referência à sua rentabilidade, é tanto maior, quanto mais intensiva for a sua atividade econômica, ou quanto mais capital for investido em área equivalente".

Portanto, evidenciou-se que o baixo preço da terra foi razão inconteste para a instalação dos graníferos em Uruçuí que, por sua vez, redundou no aprofundamento da concentração da propriedade fundiária. Destarte, os horizontes abertos para o agronegócio comportaram as condições para a reprodução do capital, como também redesenharam a organização produtiva da agricultura, pois instituiu novas relações para o trabalho, o uso da terra e a interface com o meio ambiente, inclusive manifestou a inserção da produção na competição dos mercados doméstico e global. Não é por acaso que Elias (2006) defende que tal movimento de mudanças ampliou a dialética de produção do espaço agrícola, à medida que organizam-se redes técnicas (infraestruturas), sustentadas na utilização intensiva de capital, tecnologia e informação, revelando, então, o dinamismo do redimensionamento produtivo da agropecuária.

A respeito da infraestrutura, consistia numa importante estratégia pública e privada para a territorialização do capital em Uruçuí, como explicou um empreendedor agrícola de 56 anos, natural do estado do Paraná.

Hoje, se você consegue produzir uma quantidade de 45, 50, 55 sacas por hectare, isso tem tudo a ver com o agronegócio. Ou seja, se não tivesse insumos na região, se não tivesse sementes na região, se não tivesse máquinas apropriadas na região, tu [empreendedor] não ia ter um agronegócio. Ou seja, deve-se à infraestrutura. [...] não ia ter um banco pra te financiar, [...] não ia ter uma empresa forte que nem essa aí [Bunge Alimentos S.A.] para financiar os produtores. Então, uma coisa engloba a outra [...] (Comunicação oral).

De fato, inferiu-se, por meio do trabalho empírico, que a disponibilidade de infraestruturas representava um mecanismo subvencionador para atração de empresas de agronegócios para Uruçuí, na medida em que potencializava a escala da produção, o que confirmou a crítica de Bernardes (2015), de que a criação de infraestruturas materializa os custos envolvidos na implantação das condições gerais da acumulação capitalista na fronteira.

Evidentemente, coube ao Estado a função de viabilizar a entrada da agricultura empresarial em Uruçuí, pois alicerçado em Monteiro e Aguiar (2006), o ingresso do município na nova lógica produtiva ocorreu a partir da década de 1990, com a formulação de políticas estatais de cunho regional, como o FINOR-Agropecuário e o Fundo Constitucional de Financiamento do Nordeste (FNE) que cumpririam o objetivo de sustentar o desenvolvimento agropecuário (com aquisição e melhoramento de rebanhos, cultivo de pastagens, formação de áreas de extrativismo, etc.) e florestal (principalmente caju) nos cerrados piauienses. Todavia, 
segundo Silva (2016), os resultados não foram satisfatórios, uma vez que tanto os projetos agropecuários como as plantações de caju foram substituídos por lavouras modernas.

Monteiro e Aguiar (2006) destacam também a criação, em 1993, do Programa Nordeste Competitivo, cuja responsabilidade era do Banco Nacional de Desenvolvimento Econômico e Social (BNDS), e os adventos, em 1996, da Lei no 4.859, de 27 de agosto, que concedia isenção fiscal sob o Imposto sobre Circulação de Mercadorias e Prestação de Serviços de Transporte Interestadual e Intermunicipal e de Comunicação (ICMS), entre 60 a 100\%, em até 15 anos, conforme o tipo de empresa que desejasse se instalar, e em 1998, do Polo de Desenvolvimento Integrado Uruçuí/Gurgueia, tributado à estratégia do governo federal, que por meio do Banco do Nordeste do Brasil estipulou metas (até o ano de 2003) para a construção de uma política de desenvolvimento territorial nos cerrados do sul do Piauí.

Portanto, para Monteiro e Aguiar (2006), Peixinho e Scopel (2009) e Silva (2016), tais arranjos institucionais resultaram, por um lado, na modernização da agropecuária, na instalação de indústrias e agroindústrias, no crescimento da produtividade e na expansão da fronteira agrícola (via valorização especulativa das terras); e por outro lado, na manutenção de grandes propriedades rurais, o que alterou o sentido de reprodução da atividade primária, ao substituírem a cultura extensiva por intensiva.

Ademais, destaca-se que não obstante o baixo preço da terra e a infraestrutura como mecanismos preeminentes de propagação do agronegócio em Uruçuí, faz-se mister realçar que $100 \%$ dos fazendeiros reconheceram as condições de solo, clima, topografia e hidrografia, como aspectos satisfatórios à instalação no município, como enfatizou um produtor:

A gente já tinha algumas informações, por meio de amigos nossos que estavam em BalsasMA, já conheciam o Piauí e [...] passaram essas informações pra gente. Aí, quando eu vim conhecer, em 87 [1987], e [...] nós rodamos todo esse cerrado aí, daí a gente fez o negócio em 87, mas basicamente em função do preço e logicamente aliado às informações que a gente tinha na época, de clima né [...] preço, clima, topografia, água, e aí os fatos positivos né (Comunicação oral).

Tal contexto expressa que os limites e as condições favoráveis das características físicas do cerrado foram contingenciados à racionalidade do sistema de agricultura intensiva, concretizando o que Monteiro e Aguiar (2006) chamaram de "vocação agrícola" do cerrado piauiense, em razão de o território dispor de qualidades específicas para a instalação dos graníferos, como solo (predominância de latossolo vermelho/amarelo), clima (subúmido e úmido), hidrografia (potencial hídrico superficial e subterrâneo), vegetação (matas do tipo cerrado com transições com a caatinga) e topografia (platôs que possibilitam a mecanização).

Outrossim, com base na pesquisa de campo, identificou-se a preponderância do pioneirismo, por parte dos sulistas, como um sentimento ligado à ideia de povoamento, que 
despertava, em 66,7\% dos graníferos, a certeza de que o que existia em Uruçuí, sob o ponto de vista da produção capitalista, era uma economia de subsistência ou atrasada. Já os outros 33,3\% não manifestaram o sentimento, haja vista possuírem tempo de instalação recente. Essa conformação se coadunou com a análise de Peixinho e Scopel (2009), de que a visão sulista de desbravamento do bioma Cerrado, induzia à concepção de que, em Uruçuí, nada existia antes da chegada do agronegócio, pois para os outsiders (os outros, "os de fora”), o município configurava-se em um vazio econômico/populacional/cultural.

A respeito do reconhecimento da importância do preço da terra, da infraestrutura e das características geoambientais, realça-se o desempenho do mercado consumidor na performance dos graníferos, especialmente o regional, como esclareceu um fazendeiro.

\begin{abstract}
Outro fato que veio se confirmar depois, mais pra frente, é a gente [sulistas] ter um mercado Nordeste [consumidor final] bastante comprador, questão de milho[...] escoar a produção, é [...] com mais facilidade e com preço até melhor que o Centro-Oeste, porque a agricultura do Nordeste [agricultura empresarial], quem não conhece, ela é bastante forte, não como o Sul, mas ela é bastante forte, e onde estão instaladas as agriculturas do Nordeste não é basicamente áreas de produção de milho né, que estão no Ceará, no Rio Grande do Norte, no Pernambuco, na Paraíba (Comunicação oral).
\end{abstract}

Portanto, ressalta-se que a potencialidade e efetividade do agronegócio em Uruçuí fundamentaram-se na relação terra/infraestrutura/geoambiente/mercado, o que exigiu novos significados para o trabalho agrícola e novas práticas socioprodutivas.

A pesquisa de campo apontou que o uso intensivo de inovações tecnológicas, como mecanização, insumos químicos e sementes melhoradas (sobretudo, soja), era largamente disseminado entre os empreendedores agrícolas, haja vista que $100 \%$ justificaram o manejo em razão de ganhos em produtividade.

A análise de mão de obra utilizada pela agricultura empresarial revelou a presença de uma divisão social do trabalho, ao demonstrarem a hierarquização das tarefas, segundo a complexidade do sistema técnico envolvido. Nesse sentido, verificou-se que $100 \%$ dos empreendedores agrícolas contratavam pouca força de trabalho para as operações produtivas.

A respeito dessa divisão do trabalho, a pesquisa se embasou na classificação elaborada por Ferreira (2009), acerca da relação entre a ocupação dos serviços e o nível de qualificação ou condição educacional dos trabalhadores. Para tanto, descreveu que a entrada de trabalhadores nas fazendas se orientava por meio da personificação de tipologias, como "baixa qualificação", "ensino médio" e "elevada qualificação".

Desta forma, identificou-se que o quadro de pessoal nos empreendimentos graníferos se distinguia em 55,2\% de trabalhadores de baixa qualificação, os quais exerciam as atividades menos valorizadas, principalmente os serviços gerais, com isso, na medida em que a demanda por 
produtividade crescia, elevavam-se as contratações temporárias, e quanto mais essa era concluída, os mesmos eram demitidos; $37,4 \%$ de trabalhadores que possuíam o ensino médio, relacionavam-se diretamente às funções de plantio e colheita, em decorrência da familiaridade com os equipamentos técnicos e, da compreensão da lógica produtiva, esse segmento era constituído por profissionais, como chefes de campo $(7,4 \%)$ e operadores de máquinas $(30,0 \%)$; e 7,4\% de trabalhadores com elevada qualificação, que preenchiam as vagas de maior nível de escolaridade, como agrônomos e gerentes de campo.

Tal contexto se coadunou com a concepção de Arruzzo (2009), de que a qualificação exigida atuaria como um mecanismo seletivo e excludente, já que restringia os trabalhadores originários da agricultura familiar (historicamente carentes de escolaridade) do contato dos objetos técnicos. Dessa maneira, pontuou-se que a permanência de trabalhadores de baixa qualificação nas fazendas, representava a expulsão dos que não detinham a propriedade da terra e/ou os meios para utilizá-la, e revelava um cenário de conflitos sociais a que muitos agricultores familiares estavam expostos, já que por não conseguirem a subsistência do grupo doméstico unicamente pelo produto do seu trabalho na unidade de produção familiar, eram obrigados a se assalariarem, em determinados períodos do ano, nas grandes propriedades.

Nesse sentido, entendeu-se porque Moraes (2009) e Silva (2016) defendem que a territorialização da agricultura empresarial em Uruçuí interferiu nas estratégias econômicas e sociais de sobrevivência das populações tradicionais do cerrado, como os camponeses e agricultores familiares, segundo uma racionalidade única e excludente de reprodução das condições de vida. Isto é, embasada na reprodução pura e simples do trabalho familiar ou como produto integrado ao agronegócio, ao redefinirem as identidades socioculturais e sociabilidades no sistema agrícola familiar.

Outrossim, conferiu-se que quanto ao grau de instrução e a quantidade de trabalhadores empregados nos empreendimentos, em Uruçuí o agronegócio se manifestava de maneira contraditória, pois à medida que intensificava o incremento do aparato tecnológico, diminuía a demanda por postos de trabalho, gerando novos perfis de mão de obra.

Nessa perspectiva, compreendeu-se que o processo de territorialização provocado pela agricultura empresarial em Uruçuí socializava interesses confluentes e divergentes da produção do espaço geográfico, por revelar as posições e oposições das relações de poder inscritas na ocupação capitalista do território. 


\section{CONSIDERAÇÕES FINAIS}

Constatou-se que os motivos para a instalação dos graníferos em Uruçuí se referiam, $a$ priori, ao baixo preço das terras, às condições geoambientais e à existência de um mercado regional. E a posteriori, vinculavam-se à infraestrutura implantada para financiar, produzir, armazenar e distribuir as mercadorias, bem como a ampliação da participação do país no mercado internacional, tendo o Estado papel relevante nesse processo.

Salienta-se que as ações institucionais resultaram, por um lado, na modernização da agropecuária, na construção de indústrias e agroindústrias, na elevação da produtividade da terra, tornando a soja a principal mercadoria, e na configuração de um mercado de terras assentado na valorização especulativa do espaço rural; e, por outro lado, na permanência de grandes propriedades fundiárias, o que modificou o sentido da reprodução da atividade primária, ao substituírem a cultura extensiva pela intensiva.

De fato, a ocupação capitalista acarretou profundos impactos sociais e territoriais, que culminaram na concentração da propriedade da terra, em transformações das relações de trabalho, expulsão dos trabalhadores das chapadas e em incertezas quanto à sustentabilidade dos recursos naturais e à preservação das identidades culturais.

Portanto, reconheceu-se que a internalização das inovações tecnológicas nas fazendas do agronegócio, exprimiu as rugosidades espaciais do processo de territorialização do capital na agricultura, como a concentração da riqueza, a seletividade socioespacial e a subordinação da força de trabalho originária da pequena propriedade, o que destituiu a lógica do cerrado como lugar de vida e de trabalho (no sentido posto pelas populações nativas), passando a operar a retórica de um ambiente voltado para a produção e mercado, isto é, um espaço com valor de troca, cuja máxima calca-se na reprodução do capital.

\section{REFERÊNCIAS}

ALVES, V. E. L. As bases históricas da formação territorial piauiense. Geosul, Florianópolis, v. 18, n. 36, p. 55-76, jul./dez., 2003.

ALVES, V. E. L. Os cerrados piauienses e sua nova lógica de reprodução capitalista. In: ELIAS, D.; PEQUENO, R. (Orgs.). Difusão do agronegócio e novas dinâmicas socioespaciais. Fortaleza: Banco do Nordeste do Brasil, 2006, pp. 235-258.

ALVES, V. E. L. As novas dinâmicas socioespaciais introduzidas pelo agronegócio nos cerrados da Bahia, Maranhão, Piauí e Tocantins. In: BERNARDES, J. A.; BRANDÃO FILHO, J. B. (Orgs.). A territorialidade do capital: geografias da soja II. Rio de Janeiro: Arquimedes Edições, 2009, pp.151-175. 
AGUIAR, T. de J. A; MONTEIRO, M. do S. L. Modelo agrícola e desenvolvimento sustentável: a ocupação do cerrado piauiense. Ambiente \& Sociedade, Campinas, v. 8, n. 2, jul./dez., 2005.

ANDRADE, M. C. de. Territorialidades, desterritorialidades, novas territorialidades: os limites do poder nacional e do poder local. In: SANTOS, M.; SOUZA, M. A. de; SILVEIRA, M. L. (Orgs.). Território: globalização e fragmentação. São Paulo: Hucitec, 1994. pp. 213-220.

ARRUZZO, R. C. O moderno e o arcaico no trabalho na agricultura moderna nos cerrados do Norte e Nordeste do Brasil. In: BERNARDES, J. A.; BRANDÃO FILHO, J. B. (Orgs.). A territorialidade do capital: geografias da soja II. Rio de Janeiro: Arquimedes, 2009. p. 56-68.

BABY-COLLIN, V.; CORTES, G. MIRET, N.; SASSONE, S. Visibilidad y territorialización de la migración boliviana en Madrid, Barcelona y Buenos Ayres. In: RÚBIES, I. P.; CARRASCO, J. B.; COLL, A. G.; GIL, F.; VILlANUEVA, C. L.; AGUILERA, D. S.; BENDITO, T. V. (Editores). Población y espacios urbanos. Barcelona: Departament de Geografía Humana/UB; Grupo de Población (AGE), 2011. pp. 557-576.

BERNARDES, J. A. Fronteiras da agricultura moderna no cerrado Norte/Nordeste: descontinuidades e permanências. In: BERNARDES, J. A.; BRANDÃO FILHO, J. B. (Orgs.). A territorialidade do capital: geografias da soja II. Rio de Janeiro: Arquimedes Edições, 2009. pp.13-39.

BERNARDES, J. A. Novas fronteiras do capital no cerrado: dinâmica e contradições da expansão do agronegócio na região Centro-Oeste, Brasil. Scripta Nova - Revista Electrónica de Geografía y Ciencias Sociales, Barcelona, v. XIX, p. 507, abr., 2015.

BRANDÃO FILHO, J. B. Dilemas e desafios da pequena produção agrícola frente à expansão do agronegócio no Piauí. In: BERNARDES, J. A; BRANDÃO FILHO, J. B. (Orgs.). A territorialidade do capital: geografias da soja II. Rio de Janeiro: Arquimedes Edições, 2009. pp. 115-136.

BRASIL. Presidência da República. Lei n 8.629, de 25 de fevereiro de 1993. Dispõe sobre a regulamentação dos dispositivos constitucionais relativos à reforma agrária, previstos no Capítulo III, Título VII, da Constituição Federal. (1993). Disponível em: <http://www.planalto.gov.br/ ccivil_03/leis/L8629.htm.> Acesso em: 1 de março de 2017.

CEPRO. Fundação Centro de Pesquisas Econômicas e Sociais do Piauí. Cerrados piauienses: estudo e análise de suas potencialidades, impactos da exploração da riqueza sobre a população da região. Teresina: CEPRO, 2014.

CEPRO. Fundação Centro de Pesquisas Econômicas e Sociais do Piauí. O IDHM dos municípios do Piauí por território de desenvolvimento. Teresina: Fundação CEPRO, 2016.

COMERCI, M. E. “Tenemos que ir Allá y pegar la vuelta". Continuidades y cambios en las prácticas de movilidad campesinas en contextos de conflictividad emergente. Revista Transporte y territorio, Buenos Ayres, n. 3, p. 77-102, 2010. 
CONAMA. Conselho Nacional do Meio Ambiente. Resolução no 237, de 19 de dezembro de 1997. Dispõe sobre a revisão e complementação dos procedimentos e critérios utilizados para o licenciamento ambiental. (1997). Disponível em: <http://www.mma.gov.br/port/conama/ legiabre.cfm?codlegi=237> . Acesso em: 10 de março de 2017.

CORREAA, R. L. Espaço: um conceito-chave da geografia. In: CASTRO, I. E. de; GOMES, P. C. da C.; CORRÊA, R. L. (Orgs.). Geografia: conceitos e temas. 8. ed. Rio de Janeiro: Bertrand Brasil, 2006. pp. 15-47.

DANTAS, F. Mapa da localização geográfica dos empreendimentos graníferos em Uruçuí/PI. Teresina, 2017. 1 mapa color. Escala 1:50 km.

ELIAS, D. Globalização e fragmentação do espaço agrícola no Brasil. Scripta Nova - Revista Electrónica de Geografía y Ciencias Sociales, Barcelona, v. X, n. 218, p. 3, ago., 2006.

FERREIRA, M. da G. R. Repercussões da expansão da agricultura moderna sobre a pequena produção no Sul do Maranhão. In: In: BERNARDES, J. A.; BRANDÃO FILHO, J. B. (Orgs.). A territorialidade do capital: geografias da soja II. Rio de Janeiro: Arquimedes Edições, 2009. pp. 69-88.

FLORIANI, N.; RÍOS, F. T.; FLORIANI, D. Territorialidades alternativas e hibridismo no mundo rural: resiliência e reprodução da sociobiodiversidade em comunidades tradicionais do Brasil e Chile meridionais. Polis - Revista de la Universidad Bolivariana, Santiago, v. 12, n. 34, p. 73-94, abr., 2013.

HAESBAERT, R. Des-caminhos e perspectivas do território. In: RIBAS, A. D.; SPOSITO, E. S.; SAQUET, M. A. (Orgs.). Território e desenvolvimento: diferentes abordagens. Francisco Beltrão: Unioeste, 2004. pp. 87-119.

HAESBAERT, R. De espaço e território, estrutura e processo. Economía, Sociedad y Territorio, Toluca, v. 13, n. 43, p. 805-815, sep./dic., 2013.

IBGE. Instituto Brasileiro de Geografia e Estatística. Censo demográfico 2010 (Piauí). Características da população e dos domicílios. Resultados do universo. Rio de Janeiro: IBGE, 2010.

IBGE. Instituto Brasileiro de Geografia e Estatística.Manual técnico da vegetação brasileira: sistema fitogeográfico, inventário das formações florestais e campestres, técnicas e manejo de coleções botânicas, procedimentos para mapeamentos. 2. ed. Rio de Janeiro: IBGE, 2012.

IBGE. Instituto Brasileiro de Geografia e Estatística. Base cartográfica contínua, ao milionésimo (BCIM): versão 4.0. Rio de Janeiro, 2014.

IBGE. Instituto Brasileiro de Geografia e Estatística.SIDRA: bancos de dados agregados sobre a produção agrícola municipal de Uruçuí entre 1990 e 2014. (2015). Disponível em: <www.Ibge.gov.br>. Acesso em 10 de setembro de 2017.

IBGE. Instituto Brasileiro de Geografia e Estatística. Histórico de Uruçuí. (2017). Disponível em: <www.ibg.gov.br.> Acesso em: 15 de agosto de 2017. 
INCRA. Instituto Nacional de Colonização e Reforma Agrária. Instrução especial/INCRA no 20. Estabelece o módulo fiscal de cada município, previsto no Decreto ${ }^{\circ} 84.685$, de 06 de maio de 1980. Disponível em: <http://www.incra.gov.br/sites/default/files/uploads/institucionall/legislacao-/atos-internos/instrucoes/ie20_280580.pdf>. Acesso em: 1 de março de 2017.

INCRA. Instituto Nacional de Colonização e Reforma Agrária. Estrutura fundiária do Piauí por município. Teresina: INCRA (Superintendência regional do Piauí - SR 24), 2013.

KAUTSKY, K. A questão agrária. São Paulo: Nova Cultural, 1986.

KIRSCHBAUM, C. Decisões entre pesquisas quali e quanti sob a perspectiva de mecanismos causais. Revista Brasileira de Ciências Sociais, São Paulo, v. 28, n. 82, p. 179-257, jun., 2013.

LOPES, J. R. B. Do latifúndio à empresa: unidade e diversidade do capitalismo no campo. Rio de Janeiro: Centro Edelstein de Pesquisas Sociais, 2008.

MENESTRINO, E.; PARENTE, T. G. O estudo das territorialidades dos povos tradicionais impactados pelos Empreendimentos Hidrelétricos no Tocantins. Brazilian Geographical Journal: Geosciences and Humanities Research Medium, Uberlândia, v. 2, n. 1, p. 1-19, jan./jun., 2011.

MONTEIRO, M. do S. L.; AGUIAR, T. de J. A. Ocupação do cerrado piauiense: valorização fundiária e consequências ambientais. In: ELIAS, D. de S.; PEQUENO, R. (Orgs.). Difusão do agronegócio e novas dinâmicas socioespaciais. Fortaleza: Banco do Nordeste do Brasil, 2006. pp. 211-233.

MORAES, M. D. C. de. Do destino pastoril à vocação agrícola: modernização agrícola dos cerrados e inflexões discursivas nas narrativas mestras do Piauí. In: ELIAS, D.; PEQUENO, R. (Orgs.). Difusão do agronegócio e novas dinâmicas socioespaciais. Fortaleza: Banco do Nordeste do Brasil, 2006. pp. 173-209.

MORAES, M. D. C. de. Um povo do cerrado entre baixões e chapadas: modo de vida e crise ecológica de camponeses(as) nos cerrados do sudoeste piauiense. In: GODOI, E. P. de; MENEZES, M. A. de; MARIN, R. A. (Orgs.). Diversidade do campesinato: expressões e categorias. v. 2 (estratégias de reprodução social). São Paulo: Unesp; Brasília: Núcleo de Estudos Agrários e Desenvolvimento Rural, 2009. pp. 131-161.

ORLANDI, E. P. Análise do discurso: princípios e procedimentos. Campinas: Pontes, 2000.

PEIXINHO, D. M.; SCOPEL, I. A territorialização da agricultura moderna no Piauí. In: BERNARDES, J. A.; BRANDÃO FILHO, J. B. (Orgs.). A territorialidade do capital: geografias da soja II. Rio de Janeiro: Arquimedes Edições, 2009. pp. 89-113.

RAFFESTIN, C. Repères pour une théorie de la territorialité humaine. Cahier/Groupe Réseaux, Paris, n. 7, p. 2-22, jan., 1987.

RIBEIRO, D. D.; MENDOÇA, M. R.; HESPANHOL, A. N. Relações de trabalho na agricultura mecanizada: a monocultura da soja em Goiás. Scripta Nova - Revista Electrónica de Geografía y Ciencias Sociales, Barcelona, v. VI, n. 119, p. 81, ago., 2002. 
SABOURIN, E. Camponeses do Brasil: entre a troca mercantil e a reciprocidade. Rio de Janeiro: Garamond, 2009.

SACK, R. Human territoriality: its theory and history. Cambridge: Cambridge University Press, 1986.

SAQUET, M. A. O território: diferentes interpretações na literatura italiana. In: RIBAS, A. D.; SPOSITO E. S.; SAQUET, M. A. (Orgs.) Território e desenvolvimento: diferentes abordagens. Francisco Beltrão: Unioeste, 2004. pp.121-147.

SANTOS, I. E. dos. Manual de métodos e técnicas de pesquisa cientifica. 9. ed. Niterói: Impetus, 2012.

SILVA, A. J. da. Agricultura familiar e a territorialização/desterritorialização/ reterritorialização provocada pelo agronegócio no cerrado piauiense: hibridismo sociocultural marginal em Uruçuí. 326 f. Tese (Doutorado em Desenvolvimento e Meio Ambiente), Universidade Federal do Piauí, Teresina, 2016.

SILVA, A. J. da; MONTEIRO, M. S. L.; BARBOSA, E. L. Nova dinâmica produtiva e velhas questões territoriais nos cerrados setentrionais do Brasil. Revista Espacios, Caracas, v. 36, n. 21, p. $14,2015$.

SILVA, A. J. da; MONTEIRO, M. S. L.; BARBOSA, E. L. Contrapontos entre o tradicional e o moderno no rural. Boletim de Geografia, Maringá, v. 34, n. 2, p. 81-97, 2016.

SILVA, A. J. da; MONTEIRO, M. S. L.; BARBOSA, E. L. Rugosidades da territorialização do capital na expansão da fronteira agrícola no sudoeste piauiense. In: QUIRÓS, R. R. (Org.). Tierra: naturaleza, biodiversidad y sustentabilidad. 1. ed. San José, Costa Rica: Jade, 2017, pp. 860-869.

SILVA, A. J. da; MONTEIRO, M. do S. L.; SILVA, M. V. da. Contrapontos da consolidação do agronegócio no cerrado brasileiro. Sociedade e Território, Natal, v. 27, n. 3, p. 95-114, jul./dez., 2015.

SPOSITO, E. S. Geografia e filosofia: contribuição para o ensino do pensamento geográfico. São Paulo: Unesp, 2004.

VERÓNICA, A. M.; SOTOMAYOR, M. A. ¿Confidencialidad, anonimato?: las otras promesas de la investigación. Acta Bioethica, Santiago, v. 17, n. 2, p. 199-204, nov., 2011. 